\title{
Research on International Ship Dangerous Cargo Transportation
}

\author{
Xiuping Sui \\ Shandong Jiaotong University, Shandong, China \\ WHSUI@163.com
}

Keywords: Fuzzy assessment; AHP; Dangerous Cargo

\begin{abstract}
Firstly, this paper summarizes the risk of dangerous goods transportation at home and abroad, and determines the risk factors that affect the safety of dangerous goods transportation on the basis of relevant theoretical research. Then compare the risk evaluation methods, select the Fuzy-AHP method, combine the data survey and collection of the actual situation of the enterprise in the transportation process, and establish an evaluation index system from some aspects: people, equipment, dangerous goods, environment and management. According to the AHP method, the index weight is determined and calculated
\end{abstract}

\section{Introduction}

China is a major country in the production and transportation of dangerous goods. More than $95 \%$ of dangerous goods involve transportation from other places. A large amount of chemical raw materials and products need to be distributed throughout the country through various modes of transportation, taking into account infrastructure investment, transportation volume, and transportation costs. Navigation transportation has become the best choice among many modes of transportation. The Navigation transportation of dangerous goods has corresponding transportation requirements for enterprises and ships, and dangerous chemicals have their own dangerous characteristics such as flammable, explosive, and corrosive. Once dangerous goods transported by water are involved in accidents, the economic losses are even more serious and the social impact is great. Therefore, the safety of dangerous goods transportation in the navigation transportation industry has become the focus of attention of all parties.

Firstly, this paper summarizes the risk of dangerous goods transportation at home and abroad, and determines the risk factors that affect the safety of dangerous goods transportation on the basis of relevant theoretical research. Then compare the risk evaluation methods, select the Fuzy-AHP method, combine the data survey and collection of the actual situation of the enterprise in the transportation process, and establish an evaluation index system from some aspects: people, equipment, dangerous goods, environment and management. According to the AHP method, the index weight is determined and calculated. Finally, a fuzzy comprehensive evaluation model is constructed to evaluate the risk of dangerous goods transportation in the enterprise.

\section{Introduction of Analytic Hierarchy Process}

This is established by Professor Saaty T L, an American movement coordinator of the Analytic Hierarchy Process, it is a method of quantitative analysis of the evaluation object, but it has more qualitative characteristics than the general quantitative analysis method. Reasonable and effective combination of quantitative and qualitative, through the brain simulation of judgment and decision-making, and the impact of factors in each level of the system on the results are quantified, can clearly make multi-objective comprehensive evaluation. A comprehensive index system of evaluation factors is established. According to the evaluation object, the evaluation index is established, and various influencing factors are decomposed into multiple hierarchical structures. 


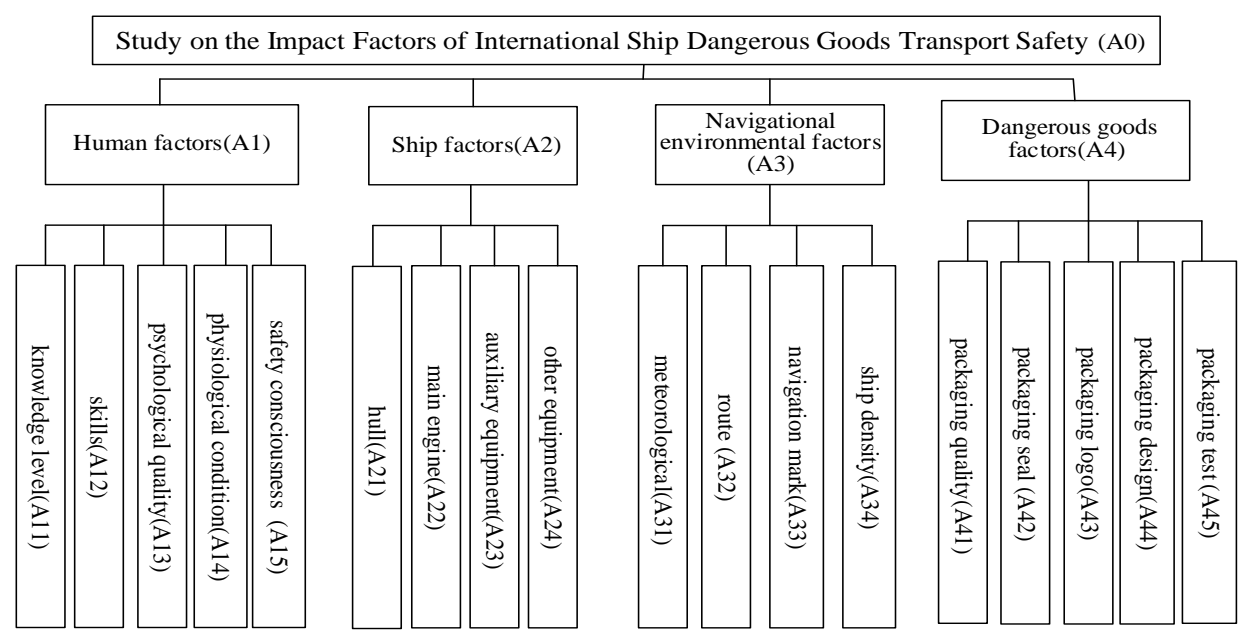

Figure 1. International Ship Dangerous Cargo Model

\section{Judgment matrix Established}

According to the first step, the judgment matrix is established to compare the factors of the same layer and the upper layer. The relative importance of each factor in each layer is judged, and the scale of $\mathrm{L}$ to 9 is used to score. The judgment matrix of a certain level factor relative to the previous level is constructed.

\begin{tabular}{|l|l|l|l|l|}
\hline $\mathrm{A} 0$ & $\mathrm{~A} 1$ & $\mathrm{~A} 2$ & $\mathrm{~A} 3$ & $\mathrm{~A} 4$ \\
\hline $\mathrm{A} 1$ & 1.0000 & 1.0000 & 2.0000 & 0.5000 \\
\hline $\mathrm{A} 2$ & 1.0000 & 1.0000 & 0.5000 & 0.5000 \\
\hline $\mathrm{A} 3$ & 0.5000 & 2.0000 & 1.0000 & 1.0000 \\
\hline $\mathrm{A} 4$ & 2.0000 & 2.0000 & 1.0000 & 1.0000 \\
\hline
\end{tabular}

The result of calculation is as follow:

$\mathrm{CI}=0.0831 \quad \mathrm{CR}=0.0923$

The contrast matrix A0 passes the consistency test, and each vector weight vector $\mathrm{W}$ is:

$$
\mathrm{W}=\left(\begin{array}{llll}
0.2536 & 0.1672 & 0.2448 & 0.3344
\end{array}\right) \quad \lambda_{\max }={ }_{4.2492}
$$

\begin{tabular}{|l|l|l|l|l|l|}
\hline A1 & A11 & A12 & A13 & A14 & A15 \\
\hline A11 & 1.0000 & 2.0000 & 3.0000 & 2.0000 & 2.0000 \\
\hline A12 & 0.5000 & 1.0000 & 2.0000 & 3.0000 & 3.0000 \\
\hline A13 & 0.3333 & 0.5000 & 1.0000 & 1.0000 & 3.0000 \\
\hline A14 & 0.5000 & 0.3333 & 1.0000 & 1.0000 & 1.0000 \\
\hline A15 & 0.5000 & 0.3333 & 0.3333 & 1.0000 & 1.0000 \\
\hline
\end{tabular}

The result of calculation is as follow:

$\mathrm{CI}=0.0697 \quad \mathrm{CR}=0.0622$

The contrast matrix A1 passes the consistency test, and each vector weight vector $\mathrm{W}$ is:
$\mathrm{W}=(0.3439$
0.2722
0.1590
0.1225
0.1024) $\lambda_{\max }=$
5.2786

\begin{tabular}{|l|l|l|l|l|}
\hline $\mathrm{A} 2$ & $\mathrm{~A} 21$ & $\mathrm{~A} 22$ & $\mathrm{~A} 23$ & $\mathrm{~A} 24$ \\
\hline $\mathrm{A} 21$ & 1.0000 & 0.2500 & 1.0000 & 3.0000 \\
\hline $\mathrm{A} 22$ & 4.0000 & 1.0000 & 0.5000 & 2.0000 \\
\hline $\mathrm{A} 23$ & 1.0000 & 0.2000 & 1.0000 & 1.0000 \\
\hline $\mathrm{A} 24$ & 0.3333 & 0.5000 & 1.0000 & 1.0000 \\
\hline
\end{tabular}

The result of calculation is as follow:

$\mathrm{CI}=0.0091 \quad \mathrm{CR}=0.0101$ 
The contrast matrix A3 passes the consistency test, and each vector weight vector $\mathrm{W}$ is:
$\mathrm{W}=(0.2412$
0.4461
0.1597
$0.1530)$
$\lambda_{\mathrm{max}}=4.0273$

\begin{tabular}{|l|l|l|l|l|}
\hline A3 & A31 & A32 & A33 & A34 \\
\hline A31 & 1.0000 & 2.0000 & 3.0000 & 2.0000 \\
\hline A32 & 0.5000 & 1.0000 & 2.0000 & 3.0000 \\
\hline A33 & 0.3333 & 0.5000 & 1.0000 & 1.0000 \\
\hline A34 & 0.5000 & 0.3333 & 1.0000 & 1.0000 \\
\hline
\end{tabular}

The result of calculation is as follow:

$\mathrm{CI}=0.0344 \quad \mathrm{CR}=0.0382$

The contrast matrix A3 passes the consistency test, and each vector weight vector $\mathrm{W}$ is:
$\mathrm{W}=(0.4192$
0.2970
0.1394
$0.1444)$
$\lambda_{\max }=$
4.1031

\begin{tabular}{|l|l|l|l|l|l|}
\hline A4 & A41 & A42 & A43 & A44 & A45 \\
\hline A41 & 1.0000 & 1.0000 & 4.0000 & 2.0000 & 2.0000 \\
\hline A42 & 1.0000 & 1.0000 & 2.0000 & 1.0000 & 3.0000 \\
\hline A43 & 0.2500 & 0.5000 & 1.0000 & 1.0000 & 3.0000 \\
\hline A44 & 0.5000 & 1.0000 & 1.0000 & 1.0000 & 1.0000 \\
\hline A45 & 0.5000 & 0.3333 & 0.3333 & 1.0000 & 1.0000 \\
\hline
\end{tabular}

The result of calculation is as follow:

$\mathrm{CI}=0.0850 \quad \mathrm{CR}=0.0759$

The contrast matrix A4 passes the consistency test, and each vector weight vector $\mathrm{W}$ is:
$\mathrm{W}=(0.3246$
0.2561
0.1571
0.1569
0.1053) $\lambda_{\max }=$
5.3401

Impact Factors of International Ship Dangerous Goods Transport Safety about the first class includes Human factors, Ship factors, Navigational environmental factors, Dangerous goods, factors. Dangerous goods,factor is important.In the second class indicators, among human factors, safety consciousness is important. Among ship factors, main engine is important. Among navigational environmental factors, meteorological factor is important. Among dangerous goods factors, packaging quality is important

\section{Conclusion}

The safety of dangerous goods waterway transportation is closely related to the safety of ports, dock operations areas, marine ecosystems, and personal property, while dangerous goods waterway accidents involve a wide range of areas and have a wide range of impacts. If they occur, the losses will be serious. It is necessary to strengthen the security awareness and attention of the whole society. (2) Also in the case of water transport, the obvious difference between dangerous goods and ordinary goods is that transport personnel and supervision departments must understand and master the physical and chemical properties of dangerous goods and the dangerous characteristics of dangerous goods. In recent years, the amount of dangerous goods requiring 430,000 square data for the evaluation and control of dangerous goods transportation risks by water has not been reduced, but has increased. There are many varieties, and it is necessary to strengthen professional learning: to achieve defensive loyalty.

\section{Reference}

[1] Frederic P, Philipp K, Roger S. Experience Co-creation in Financial Services:An Empirical Exploration. Journal of Service Management, 2015, 26 (2), pp.295-320.

[2] Yu Huixian. Recruitment Based on Competency Model[J].Chinese and Foreign Exchanges, 2017,(17): 30 
[3] Assante M, Candela L, Castelli D. Are Scientific Data Repositories Coping with Research Data Publishing. Data Science Journal, 2016(15), pp.1-24.

[4] Dnyandeo Dattatraya Shinde, Ramjee Prasad. Application of AHP for Ranking of Total Productive Maintenance Pillars. Wireless Personal Communications, 2018, 100 (2), pp.449-462.

[5] Saeid Maknouni, Mohammad Zare, Ezzatollah Raeisi. Determining the hard rock groundwater pathway in Golgohar complex formation using hydrochemical data in AHP. Arabian Journal of Geosciences, 2018, 11 (8), pp.1-16.

[6] Arthur S. Levine, Margaret C. McDonald, Charles E. Bogosta. Sino-U.S. partnerships in research, education, and patient care: The experience of the University of Pittsburgh and UPMC. Science China Life Sciences, 2017, 60 (10), pp.1150-1156. 